\title{
Understanding the Influence of Personality Traits on Risk of Suicidal Behaviour in Schizophrenia Spectrum Disorders: A Systematic Review
}

\author{
Manuel Canal-Rivero 1,2,3, Rosa Ayesa-Arriola ${ }^{2,4}$, Esther Setién-Suero ${ }^{5} \oplus$, Benedicto Crespo-Facorro ${ }^{1,2,3}$, \\ Celso Arango ${ }^{2,6}$, Rina Dutta ${ }^{7,8,+}$ and Javier-David Lopez-Morinigo ${ }^{2,6,9,10, *,+}$ (i) \\ 1 Hospital Universitario Virgen del Rocío, 41013 Sevilla, Spain; mcanalrivero@gmail.com (M.C.-R.); \\ bcrespo@us.es (B.C.-F.) \\ 2 Centro de Investigación Biomédica en Red Salud Mental (CIBERSAM), 28029 Madrid, Spain; \\ rayesa@idival.org (R.A.-A.); carango@hggm.es (C.A.) \\ 3 Grupo de Psiquiatría Traslacional, Instituto de Biomedicina de Sevilla (IBIS), 41013 Sevilla, Spain \\ 4 Department of Psychiatry, Marqués de Valdecilla University Hospital, IDIVAL, School of Medicine, \\ University of Cantabria, 39008 Santander, Spain \\ 5 Department of Methods and Experimental Psychology, Faculty of Psychology and Education, \\ University of Deusto, 48007 Bilbao, Spain; setiensuero@hotmail.com \\ 6 Department of Child and Adolescent Psychiatry, Institute of Psychiatry and Mental Health, Hospital General \\ Universitario Gregorio Marañón, IiSGM, CIBERSAM, School of Medicine, Universidad Complutense, \\ 28029 Madrid, Spain \\ Citation: Canal-Rivero, M.; \\ Ayesa-Arriola, R.; Setién-Suero, E.; \\ Crespo-Facorro, B.; Arango, C.; Dutta, \\ R.; Lopez-Morinigo, J.-D. \\ Understanding the Influence of \\ Personality Traits on Risk of Suicidal \\ 7 Institute of Psychiatry, Psychology and Neuroscience, King's College London, London WC2R 2LS, UK; \\ rina.dutta@kcl.ac.uk \\ 8 South London and Maudsley NHS Foundation Trust, London SE5 8AZ, UK \\ 9 Departament of Psychiatry, School of Medicine, Universidad Autónoma de Madrid, 28029 Madrid, Spain \\ 10 Department of Psychiatry, Instituto de Investigaciones Sanitarias-Fundación Jiménez Díaz, \\ 28029 Madrid, Spain \\ * Correspondence: jlmorinigo@salud.madrid.org; Tel.: +34-627-277-126 \\ + Equally contributed to the study.
} Behaviour in Schizophrenia Spectrum Disorders: A Systematic Review. J. Clin. Med. 2021, 10, 4604. https:// doi.org/10.3390/jcm10194604

Academic Editor: Hilario

Blasco-Fontecilla

Received: 9 July 2021

Accepted: 4 October 2021

Published: 8 October 2021

Publisher's Note: MDPI stays neutral with regard to jurisdictional claims in published maps and institutional affiliations.

Copyright: (c) 2021 by the authors. Licensee MDPI, Basel, Switzerland. This article is an open access article distributed under the terms and conditions of the Creative Commons Attribution (CC BY) license (https:/ / creativecommons.org/licenses/by/ $4.0 /)$.
Abstract: Risk of suicidal behaviour (SB) in schizophrenia spectrum disorders (SSD) is a major concern, particularly in early stages of the illness, when suicide accounts for a high number of premature deaths. Although some risk factors for SB in SSD are well understood, the extent to which personality traits may affect this risk remains unclear, which may have implications for prevention. We conducted a systematic review of previous studies indexed in MEDLINE, PsycINFO and Embase examining the relationship between personality traits and SB in samples of patients with SSD. Seven studies fulfilled predetermined selection criteria. Harm avoidance, passive-dependent, schizoid and schizotypal personality traits increased the risk of SB, while self-directedness, cooperativeness, excluding persistence and self-transcendence acted as protective factors. Although only seven studies were retrieved from three major databases after applying predetermined selection criteria, we found some evidence to support that personality issues may contribute to SB in patients with SSD. Personality traits may therefore become part of routine suicide risk assessment and interventions targeting these personality-related factors may contribute to prevention of SB in SSD.

Keywords: personality traits; suicidal behaviour (SB); schizophrenia spectrum disorders (SSD)

\section{Introduction}

Suicide is a major public health issue, which accounts for almost one million deaths every year across the world [1]. It is of major concern that suicide rates worldwide are very likely to significantly increase in the context of the COVID-19 pandemic [2-4]. Two wellknown suicide risk factors will contribute to this. First, a rise in unemployment as a result of an economic turndown [5], which in previous economic recessions resulted in higher 
suicide rates [6]. Second, COVID-19 prevention measures are based on so-called physical distancing [7], which, although not inevitably [2], is likely to increase social isolation levels, a major suicide risk factor [8]. Suicide prevention should therefore become a public health priority in the post-COVID-19 pandemic years, which will require funding, significant effort, a multidisciplinary approach and international collaboration [9-11].

Every year almost two million people across the globe receive a first diagnosis of schizophrenia [12]. Schizophrenia is not only associated with poor clinical and social outcomes [13], but also with increased mortality [14]. Furthermore, the mortality gap between schizophrenia patients and the general population appears to have widened over the past few decades [15,16], and suicide has been demonstrated to be the strongest contributor to this excess mortality of schizophrenia $[15,17]$. Indeed, up to $5 \%$ of patients with schizophrenia die from suicide [18] and between $20 \%$ [19] and $40 \%$ of patients receiving mental healthcare who end their lives suffer from a psychotic disorder [20]. Risk of suicidal behaviour (SB) is particularly high in the first episode of psychosis (FEP) [15,21-24], although great caution is also needed ten years or longer after first presentation [23]. Specifically, there has been an increase in the incidence of reactive psychoses, i.e., a set of acute-onset and short-lived psychotic conditions triggered by psychosocial trauma [25]. In addition, social isolation-based measures for preventing COVID-19 were proposed to contribute to psychosis onset [26-28]. Moreover, so-called COVID-19-induced reactive psychosis was associated with an increased risk of suicidal behaviours [27].

In particular, two earlier meta-analyses examined risk and protective factors of SB in adults with schizophrenia [29] and in adolescents and adults with FEP [30]. Specifically, previous depression and suicide attempts, drug misuse, agitation or motor restlessness, fear of mental disintegration and poor medication compliance were found to increase suicide risk in schizophrenia [29]. In line with this, previous suicide attempts, expressed suicide ideation, greater insight, alcohol abuse, substance use, younger age of onset, younger age at first treatment, depressed mood and the duration of untreated psychosis were associated with an increased risk of deliberate self-harm before and after treatment onset in FEP [30]. On the other hand, hallucinations reduced suicide risk in schizophrenia [29]. In keeping with this, neither positive symptoms nor functioning were linked with an increased risk of deliberate self-harm in FEP [30].

This said, it should be noted that most of the studies included in the meta-analyses had a case-control design, in which odds ratios (ORs) measure the strength of the association between putative risk factors and a binary outcome, namely, SB (present vs. absent). Regardless of statistical significance, ORs $<2$ were reported to indicate a 'weak' association. Interestingly, personality and psychosocial-related factors were found to be more strongly associated with SB, i.e., higher ORs, than biological variables [31].

Of relevance, unlike non-psychotic mental disorders (see other articles published in this special issue), the potential influence of personality traits on suicide risk in schizophrenia and in FEP were not included in the above meta-analyses [29,30], which was probably owing to the low number of available studies on this topic at that time. However, premorbid personality traits may play a role in the aetiology, course and outcome of psychotic disorders [32]. In keeping with this, recent FEP studies linked specific personality traits such as fearfulness, social inhibition, shyness, immaturity, impulsivity, aggression, vulnerability and lack of coping strategies with risk of SB [33].

We conducted this up-to-date systematic review with the aim of investigating the role of personality traits in SB, defined as "a self-inflicted, potentially injurious behaviour with a nonfatal outcome for which there is evidence (either explicit or implicit) of intent to die or self-inflected death with evidence (either explicit or implicit) of intent to die" [34], in schizophrenia spectrum disorders (SSD). In particular, two hypotheses were tested: (i) that the presence of personality traits such as social inhibition, shyness, impulsivity, aggression, vulnerability and lack of coping mechanism will be associated with an increased SB risk, and (ii) based on the aforementioned editorial [31], we postulated that statistics (such as ORs) measuring the strength of these associations will be greater than 2. Although 
not very common in systematic reviews, a hypothesis-driven approach has been strongly recommended in order to appraise the quality of systematic reviews' methodology, that is, whether the research question was properly addressed [35].

\section{Materials and Methods}

We followed the Preferred Reporting Items for Systematic Reviews and Meta-Analysis (PRISMA) guidelines for the reporting of the findings of this systematic review [36].

\subsection{Search Strategy}

We conducted a literature search in MEDLINE, PsycINFO and Embase of articles that reported data on the relationship between personality traits and risk of suicidal behaviour (SB) in SSD patients, which encompasses suicide attempts and suicide completion. The terms included for the search were: "suic* OR self-harm" AND "personality traits OR temperament* OR character" AND "psychos* OR psychot* OR schizophr*". References from selected articles were cross-reviewed and selected if they met the following criteria.

\subsection{Selection Criteria}

All the abstracts from the initial search were independently screened by MCR and JDLM against the following selection criteria:

(1) Peer-reviewed articles written in English from 1 January 1993 (when the ICD-10 [37] was published) to 15 February 2021, thus ensuring that the studies included would be based on similar definitions of SSD, which are detailed below;

(2) Sample size of more than 10 patients (so case reports and case series were not included);

(3) Age: 16-64 years, both inclusive, which was decided in order to include more FEP samples;

(4) Diagnosis: 'Schizophrenia spectrum disorders', encompassing Schizophrenia, Schizoaffective Disorder and First-Episode Psychosis according to either ICD-10 [37] or DSMIV-TR [38] or DSM-5 [39] definitions;

(5) Clinical setting: In-, outpatients and mixed samples were included;

(6) Study design: both cross-sectional and cohort studies were considered;

(7) Outcome measures: data on suicide attempts and/or suicide completion had to be reported either before (cross-sectional studies) or after the study inception (cohort studies);

(8) Either a premorbid or comorbid personality assessment had to be available;

(9) No measure of the strength of the association between personality traits and SB had to be reported for the article to be included. We decided to include reports with no statistics since these studies may provide sufficient information to test hypothesis i.

In case of any doubt about meeting/not meeting the selection criteria, this would be independently resolved by two other authors (RAA and ESS), although no such discrepancies were identified between the two authors (MCR and JDLM) who conducted the articles search and selection; this was probably due to the low number of retrieved studies.

\subsection{Data Extraction}

Two authors (MCR and RAA) independently extracted all data by using a predetermined data extraction form and a web-based app for screening records in systematic reviews known as Rayyan [40]. Two other authors (ESS and JDLM) were independently contacted to resolve any inconsistencies as appropriate. The data extracted included first author and year of publication, country, setting (in- or outpatient), study design (crosssectional or longitudinal/prospective/cohort), sample size and length of follow-up where applicable, diagnostic tool, diagnosis, personality traits assessment and the strength of the association between personality-related variables and suicidal behaviour outcomes, where available. 


\subsection{Primary Outcomes}

The primary outcomes of this investigation were: (i) the association between personality traits and risk of SB (hypothesis i); and, if found, (ii) the strength of such an association (hypothesis ii).

Owing to the anticipated low number of published studies on this topic, including relevant between-study methodological differences (such as study design—cross-sectional vs. longitudinal studies-and outcomes measures), we could not apply meta-analytic techniques to results. Instead, we present a narrative review of the findings, although we used a semi-quantitative approach to test hypothesis ii (i.e., by quantitatively comparing the strength of the association between personality traits and SB across studies).

\section{Results}

\subsection{Study Selection Process}

The initial search yielded 6738 references, although after duplicate publications were removed $\mathrm{n}=5114$ articles were reviewed at a title/abstract level against the above selection criteria, following which $n=5091$ were excluded. Twenty-three articles were therefore assessed for eligibility and so the full text was reviewed. Of these, seven papers fulfilled the selection criteria and were included in the systematic review. Of note, although qualitative studies were not excluded from the search, no such studies were identified. Figure 1, below, shows the PRISMA flow chart of the study selection process.

\subsection{Characteristics of the Selected Studies}

As detailed above, seven studies were included in the systematic review. Of these, four reported an association between specific personality traits and increased levels of SB. Of relevance, all the included studies analysed the relationship between personality traits and "suicide attempts", i.e., no findings concerning the association of personality traits with suicide deaths were reported.

The first study analysed the relationship between personality traits and risk of suicide attempts in a sample of patients with SSD and was conducted in Turkey on a sample of $\mathrm{n}=94$ outpatients with schizophrenia (DSM-IV-TR criteria [38]) using a cross-sectional design [41]. The Temperament and Character Inventory (TCI) compared the Cloninger model factors between those with/without previous suicide attempts. After controlling for demographic and clinical variables, four personality features distinguished schizophrenia patients with/without history of SB. While harm avoidance (OR 7.59, 95\%CI 0.65-0.93, $p=0.006$ ) and persistence (OR 11.40, 95\% CI 0.16-0.62, $p=0.001$ ) scores increased the risk, self-directedness (OR $=6.77,95 \%$ CI 1.05-1.38, $p=0.009$ ) and cooperativeness (OR 5.88, $95 \%$ CI 1.04-1.46, $p=0.015$ ) were protective factors [41]. These findings were partially replicated by a mixed (in- and outpatients) sample of $n=161$ schizophrenia patients from Spain [42] in which, although only in males, the number of suicide attempts correlated negatively with self-directedness (OR $0.94,95 \%$ CI $0.90-0.98, p<0.05$ ) and self-transcendence (OR $0.96,95 \%$ CI $0.93-0.99, p<0.05$ ). The authors of the study hypothesised that these gender differences could be explained by the fact that males tend to struggle to regulate and adapt their behaviour, including self-reported lower levels of spirituality and universal identification than females.

A cross-sectional sample of $n=264$ adults with schizophrenia from Croatia were evaluated using the Big-Five model of personality, although no personality dimension was linked with previous SB [43].

A case-control study was conducted in Japan in which $n=87$ outpatients with schizophrenia were compared with $n=322$ healthy controls. In particular, the personality traits of a subgroup of schizophrenia patients were evaluated using the Schizotypal Personality Questionnaire. Total scores as well as interpersonal and disorganized factors were higher $(p<0.01)$ in those with previous SB than in non-attempters [44]. 


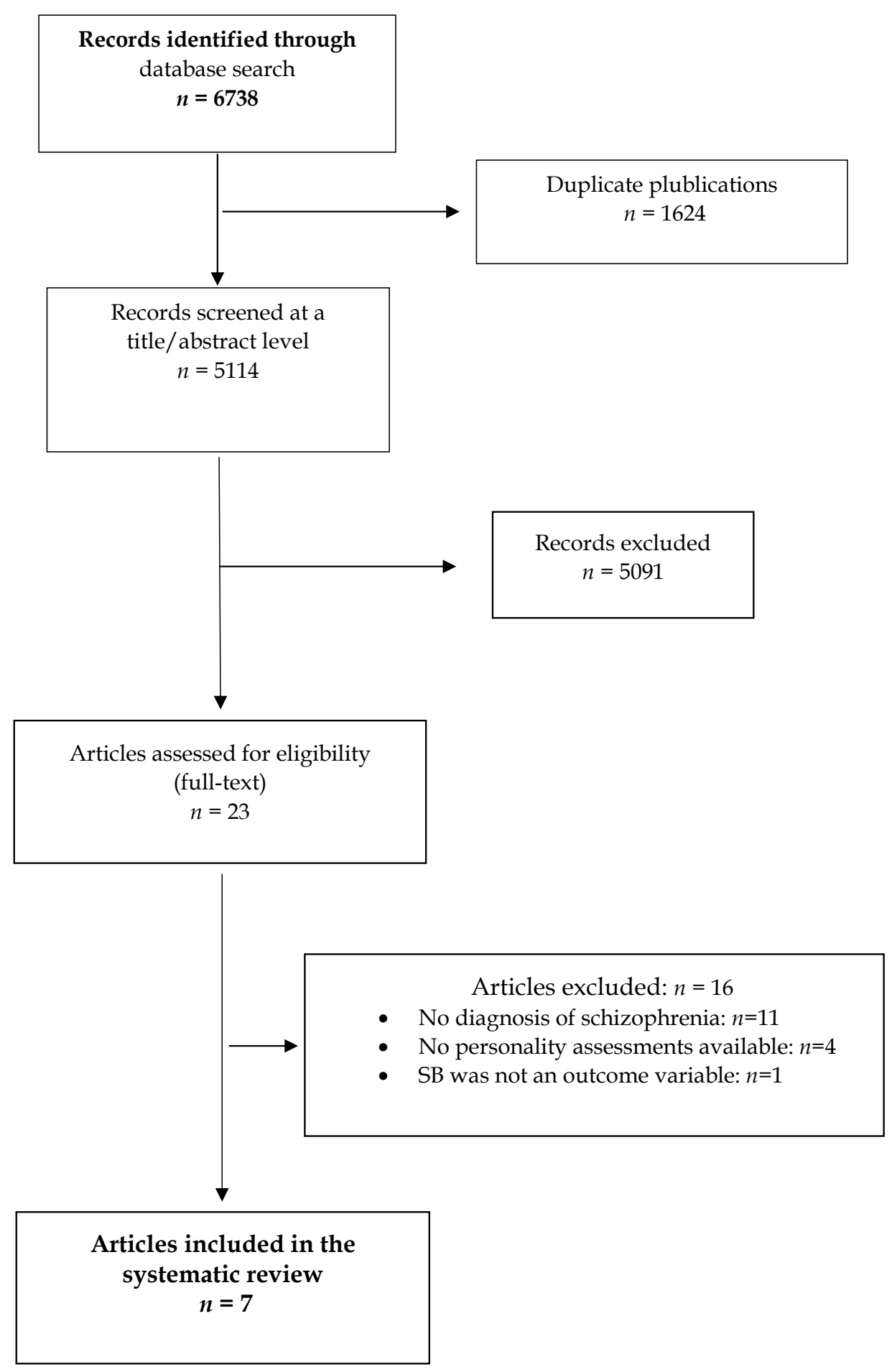

Figure 1. PRISMA flow chart of the study selection process.

Finally, a 1-year follow-up cohort of $n=65$ FEP patients from Spain examined the relationship between personality traits and diverse characteristics of SB such as occurrence, temporality and frequency, that is, three studies aiming to answer different research questions, hence providing complementary information. First, SB over the six months after the psychosis onset was predicted by passive-dependent personality traits (OR 2.42, 95\% CI 1.15-5.09, $p=0.02$ ) [33], while the presence of SB at 1-year follow-up was related to schizoid personality characteristics (OR 1.62, 95\% CI 1.02-2.57, $p=0.04$ ) [45]. Personality traits, however, did not increase risk of repeated SB over the follow-up [46].

The characteristics of the selected studies are detailed in Table 1, below. 
Table 1. Characteristics of the selected studies.

\begin{tabular}{|c|c|c|c|c|c|c|c|c|c|c|}
\hline Study & Country & Setting & Sample Size & Design & Follow-Up & Diagnosis & $\begin{array}{l}\text { Personality } \\
\text { Assessment }\end{array}$ & $\begin{array}{c}\text { SB } \\
\text { Assessment }\end{array}$ & $\begin{array}{l}\text { Did Any } \\
\text { Personality } \\
\text { Trait Increase } \\
\text { Risk of SB? }\end{array}$ & Statistical Results \\
\hline $\begin{array}{l}\text { Albayrak et al., } \\
2012 \\
{[41]}\end{array}$ & Turkey & Out & $94 \mathrm{Sch}$ & C & $\mathrm{N} / \mathrm{A}$ & Sch & $\mathrm{TCI}$ & $\begin{array}{l}\text { Unstructured } \\
\text { interviews / } \\
\text { clinical records }\end{array}$ & + & $\begin{array}{c}\text { Cooperativeness: OR 5.88, 95\%CI 1.04-1.46, } p=0.015 \text {; } \\
\text { Harm Avoidance: OR 7.59, 95\% CI 0.65-0.93, } p=0.006 \text {; } \\
\text { Excluding Persistence: OR 11.40, 95\% CI 0.16-0.62, } \\
p=0.001 \text {; Self-Directedness: OR }=6.77,95 \% \text { CI } \\
1.05-1.38, p=0.009\end{array}$ \\
\hline $\begin{array}{l}\text { Teraishi et al., } 2014 \\
\text { [44] }\end{array}$ & Japan & Out & $\begin{array}{c}87 \text { Sch322 } \\
\text { HC }\end{array}$ & C & $\mathrm{N} / \mathrm{A}$ & Sch & SPQ & $\begin{array}{l}\text { Unstructured } \\
\text { interviews/ } \\
\text { clinical records }\end{array}$ & + & $\begin{array}{l}\text { SA vs. nSA: } \\
\text { Total SPQ score: } 36.6 \pm 12.5 \text { vs. } 26.6 \pm 16.8, p=0.005 \\
\text { SPQ Interpersonal factor: } 17.4 \pm 6.9 \text { vs. } 12.6 \pm 8.1 \\
p=0.004 ; \text { SPQ Disorganized factor: } 8.7 \pm 3.6 \text { vs. } \\
5.8 \pm 4.4, p=0.003\end{array}$ \\
\hline $\begin{array}{c}\text { Miralles et al., } 2014 \\
\text { [42] }\end{array}$ & Spain & In/Out & $\begin{array}{c}161 \text { Sch214 } \\
\text { HC }\end{array}$ & C & $\mathrm{N} / \mathrm{A}$ & Sch & TCI-R & $\begin{array}{l}\text { Unstructured } \\
\text { interviews/ } \\
\text { clinical records }\end{array}$ & - & $\begin{array}{c}\text { Self-directedness (OR } 0.94,95 \% \text { CI } 0.90-0.98, p<0.05 \text { ) } \\
\text { and Self-Transcendence (OR } 0.96,95 \% \text { CI } 0.93-0.99, \\
p<0.05 \text { ) negatively correlated with number of } \\
\text { previous suicide attempts. }\end{array}$ \\
\hline $\begin{array}{l}\text { Canal-Rivero et al., } \\
2016 \\
{[33]}\end{array}$ & Spain & In & 65 FEP & $\mathrm{L}$ & 12 months & FEP & PAS & SCAN & + & $\begin{array}{l}\text { Passive-dependent personality traits associated with } \\
\text { first suicide attempt occurred 6-month after FEP } \\
\text { OR 2.42, 95\% CI 1.15-5.09, } p=0.02\end{array}$ \\
\hline $\begin{array}{l}\text { Canal-Rivero et al., } \\
2017 \\
{[45]}\end{array}$ & Spain & In & 65 FEP & $\mathrm{L}$ & 12 months & FEP & PAS & SCAN & + & $\begin{array}{c}\text { Schizoid personality traits associated with suicide } \\
\text { attempts after FEP } \\
\text { OR } 1.62,95 \% \text { CI } 1.02-2.57, p=0.04\end{array}$ \\
\hline $\begin{array}{c}\text { Jovanovic et al., } \\
2019 \\
{[43]}\end{array}$ & Croatia & In & 264 Sch & C & $\mathrm{N} / \mathrm{A}$ & Sch & BFI-10 & SIBQ & - & (2) \\
\hline
\end{tabular}

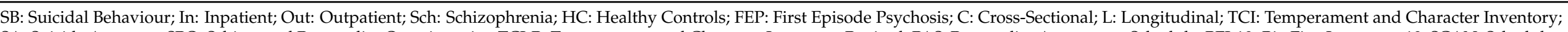

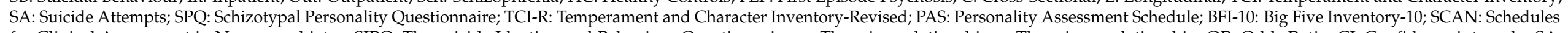

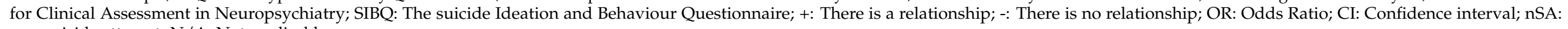
non-suicide attempt. N/A: Not applicable. 


\section{Discussion}

\subsection{Main Findings}

We aimed to investigate the role of personality traits in risk of SB in SSD patients. First of all, only seven studies could be included in the systematic review. Although this may limit the generalisability of results, at the same time the low number of included studies suggests that this topic may have been somewhat neglected by research to date. Specifically, we predicted that personality issues would be linked with an increased risk of suicidal behaviour (SB) in SSD patients (hypothesis i) and we postulated that these associations would be relatively strong (i.e., ORs $>2$ ). We found some evidence to support both hypotheses. In particular, harm avoidance, passive-dependent, schizoid and schizotypal personality traits emerged as the specific personality features associated with an increased risk of SB in schizophrenia, consistent with hypothesis $i$, while cooperativeness, excluding persistence self-directedness and self-transcendence behaved as protective factors, which was unexpected. It should be noted, however, that these findings only apply to suicide attempts, while the association of personality traits with suicide deaths remains to be investigated. Of relevance, despite the low number of selected studies, which may result in erroneously accepting the null hypothesis [33], we found some evidence of the association between personality traits and SB in SSD, which therefore provides further support for this finding. Moreover, in line with hypothesis ii, effect sizes were relatively large (most ORs $>2$ ), as discussed further below.

\subsection{Personality Issues Increased Risk of SB in SSD}

Surprisingly, the extent to which personality traits may contribute to outcomes in patients with schizophrenia, including symptomatology, functioning or SB, has scarcely been analysed [47]. However, over the past few years there has been growing research interest in better understanding the temperamental and character features of SSD subjects, given their potential implications on outcomes [48], including SB [30].

Back in 1913, Jaspers [49] suggested "psychosis onset to be a process, that is, a permanent change in a person's psychic life"; and this view appears to have dominated theoretical debate ever since, which may explain, in part, the very low number of identified studies in this systematic review. On the other hand, from a dimensional approach to psychosis, Kretschmer postulated that psychosis emerges from individual's premorbid personality [50], which would therefore have an important bearing on outcomes [48]. Our results, which revealed that harm avoidance, self-directedness, passive-dependent as well as schizoid and schizotypal personality traits increase suicide risk in patients with schizophrenia would provide partial support for Kretschmer's theories of "psychosis and premorbid personality as a continuum". In other words, our findings appear to suggest that despite previous assertions to the contrary based on Jasper's views, the onset of psychosis does not completely change premorbid personality traits, which in contrast, influence psychosis-related outcomes, including risk of SB.

More recently, the influence of personality traits on SB risk in patients with schizophrenia was investigated from three different, albeit overlapping, models [51]: (i) a five-factor model [52], (ii) the so-called psychobiological model of temperament and character [53], and (iii) the clinical or pathological personality model [54]. First, higher harm avoidance and persistence as well as lower self-directedness and cooperativeness were related to SB in a sample of schizophrenia patients [41]. Second, from a psychobiological model of temperament and character, partially replicating previous studies [41], self-directedness and self-transcendence was found to negatively correlate with SB [42]. To the best of our knowledge, only one previous study [43] employed an instrument, namely, the Big Five Inventory- 10 based on five-model factor, to explore the potential relationship between SB and personality in a sample of patients with schizophrenia. Although no association between personality traits and SB emerged from the analyses, the study authors highlighted the potential role of neuroticism in suicide-related behaviours [43]. Finally, schizoty- 
pal [44], passive-dependent [33] and schizoid traits [45] increased SB risk in patients with schizophrenia [44] and FEP [33,45].

This being said, as expected (hypothesis ii), most of the ORs concerning the association between these personality traits and risk of SB took values well above 2 . This finding should warn us further about the extent to which this topic has been neglected in research on suicide in psychosis. In particular, future studies should switch the focus from only researching putative biomarkers of $\mathrm{SB}$ to validation of more comprehensive suicide models, which, through the combination of biomarkers with psychosocial variables including personality traits, may perform better in terms of prediction. Our second hypothesis was based on a 2015 editorial, which provided a review of three decades of research on suicidal behaviour [31]. The authors highlighted the importance of the meaning of the strength of the association between two variables above and beyond conventional statistical "significance" at $p<0.05$. More specifically, the authors of this editorial suggested that the association of personality traits with SB may reach higher ORs than those emerging from analysing the biological correlates of SB. On this basis, we postulated that the strength of the association between personality traits and risk of SB would be large, which was partially supported by our findings. However, it is worth noting that personality traits were measured with scores from routine scales and questionnaires, hence as continuous variables, in all the studies included in the systematic review. As a result, high/very high ORs concerning the relationship between personality traits measured as continuous variables (i.e., scores from scales and questionnaires) and SB may actually indicate a relatively weak association between the two.

Of relevance, systematic reviews including a low number of studies may increase the risk of erroneously accepting the null hypothesis [35], that is, the lack of association between personality traits and SB. Hence, the fact that we managed to find some evidence supporting the relationship between the two (hypothesis i) based on a low number of selected studies (7) strengthens further this novel contribution to the field.

Although up to approximately $50 \%$ of SSD patients were found to fulfil criteria for a personality disorder according to one previous study [55], as noted above, personality traits in schizophrenia have received little attention from researchers. In this regard, a previous prevalence study reported dependent, narcissistic, avoidant, schizotypal and schizoid personality traits to be the most common personality traits in FEP [56]. Interestingly, our findings showed that precisely these personality traits increased SB risk, hence these subjects may represent a high-risk group, particularly in early psychosis. However, to our knowledge there are no evidence-based treatments for personality issues in SSD, an area in which further research is warranted given their implications on outcomes.

Insight, which includes illness awareness, symptom relabelling and treatment compliance [57], was postulated to increase suicide risk in early psychosis [30], although three later independent FEP cohorts did not confirm this [22,58]. One may question whether specific personality traits may be linked with higher/lower levels of insight. In this regard, a 6-month follow-up FEP study linked more severe schizoid and sociopathic personality traits with poorer insight levels [48], which was replicated by a hierarchical reanalysis of predictors of insight with the same FEP cohort [59]. Interestingly, based on two independent studies, cooperativeness, which is linked with insight [60], in addition to excluding persistence [41] and self-transcendence [42], reduced suicide risk. Hence, cooperativeness, which is associated with insight [60], as a personality trait behaved as a protective factor for suicidal behaviour. This may lead to speculation that, in contrast to the commonly held view among clinicians, insight may prevent SB in psychosis [22,58]. Early intervention services should therefore prioritise treatments for improving some insight dimensions, namely, illness awareness and symptom relabelling [58], such as metacognitive training [61]. However, some difficulties should be acknowledged when restoring insight, which is likely to require gaining mastery over them [62].

Nevertheless, each of the above personality-related variables are based on a single study, with the exception of self-directedness, which was protective [41,42]. Hence, these 
findings should be taken with cautious while awaiting replication studies. On the other hand, the use of instruments based on different theoretical models did not prevent linking common personality features, such as undefined personal goals, external organization, low self-determination, autonomy and social withdrawal, with SB in patients with SSD [63]. In addition, impaired emotional communication led to hopelessness and social isolation in FEP patients, which may affect patient safety [64].

\subsection{Strengths and Limitations}

To our knowledge, this is the first systematic review on this topic, which is of major clinical relevance. In particular, we searched three major databases, although only seven articles fulfilled the above selection criteria. Hence, this piece of work makes a novel contribution to the field, which may have implications for suicide prevention, as discussed below.

However, this review has several limitations. First, the selection criteria may have been too restrictive and the search was limited to English. In addition, we only searched three major databases (i.e., MEDLINE, EMBASE and PsycInfo). Hence, this systematic review may not include all of the articles on this topic, particularly those published in the grey literature. Although only seven studies were selected and systematic reviews including a low number of records may increase the risk of erroneously accepting the null hypothesis [35], we managed to find some evidence supporting the link between personality traits and SB, that is, the alternative hypothesis. This noted, caution is needed when interpreting the findings in terms of their generalisability. For instance, some specific personality traits were only associated with SB in one study, which therefore require replication studies. Moreover, three out of seven selected studies were based on a relatively small FEP cohort $(n=65)[33,45,46]$. However, as detailed above, results concerning personality issues and SB from these reports did not overlap each other. Second, we could not apply meta-analytic techniques to the studies' results for the reasons explained previously. However, we took a semi-quantitative approach to the interpretation of the results, which allowed us to make a more reflexive presentation of the findings. Third, some sample sizes may have been too small, thus lacking sufficient statistical power to find an association between personality traits and SB and there were relevant differences in the personality and SB assessment. Fourth, the extent to which other variables acted as confounders/mediator was unclear from some analysed studies, which requires further investigation. Fifth, although only three articles using the same FEP cohort were identified $[33,45,46]$, these reports actually tested different hypotheses. Finally, although not mandatory, PROSPERO registration of systematic reviews has been widely recommended over the past few years. Regretfully, we did not register the systematic review protocol at PROSPERO, although no differences in quality of research have been found between PROSPERO-registered and non-registered systematic reviews [65]. Nonetheless, this systematic review protocol is to be made retrospectively public in an open-access repository, such as Open Science Framework. In keeping with this, we did not evaluate the quality of selected studies, which aimed to answer different research questions. As a result, methods used by included studies varied very significantly, thus not allowing comparisons. This said, we detailed the characteristics and methodology of the seven included studies above.

\subsection{Implications on Future Research and Clinical Practice}

As noted above, only a few studies have investigated the contribution of personality issues to risk of SB in patients with SSD, and this risk is particularly high in early stages of the psychotic illness [21]. It is therefore envisioned that early intervention programmes may play a crucial role in preventing SB. Specifically, targeted interventions addressing specific risk factors and future studies measuring the extent to which these interventions reduce suicide rates in real-world conditions are warranted. Of note, caution is not only needed in early psychosis since risk of suicide in psychosis remains considerably higher a decade or even longer after first presentation [23]. 
In addition to well-known risk factors for suicide both in schizophrenia [29] and FEP [30], this systematic review revealed that, replicating findings from other mental disorders, personality appears to play a relevant role in suicide risk in SSD patients, which is the main contribution of this work. Therefore, not only personality traits should be considered as part of suicide risk assessment, but future trials testing interventions targeting harm avoidance, self-directedness, passive-dependent, schizoid and schizotypal personality traits, which may reduce suicide rates in psychosis, should also be carried out. This said, whether these personality traits may be amenable to modification is yet to be demonstrated.

In addition, the DSM-5, which was published in 2013 [39], and the upcoming ICD11 [66] have incorporated dimensional models into the classification of psychotic and personality disorders $[67,68]$. Specifically, this approach should overcome the well-recognised limitations of Kraepelin's first classification of psychotic disorders, on which previous DSM and ICD revisions were based [69]. From a research perspective, the DSM-5 and the ICD-11 may therefore pave the way towards linking specific symptoms and personality traits with biomarkers in SSD, that is, endophenotypes [70]. This may also lead to more targeted suicide risk assessment/management in SSD, a major challenge that remains unmet [19].

\section{Conclusions}

To sum up, this systematic review showed that some personality issues-harm avoidance, passive-dependent, schizoid and schizotypal personality traits-appear to increase risk of suicidal behaviour in patients with SSD, while other personality traitscooperativeness, excluding persistence and self-transcendence-acted as protective factors. Our novel findings may have implications for suicide prevention in psychosis. The inclusion of personality traits may improve the predictive value of routine clinical suicide risk assessment in settings managing patients with psychosis, although this remains to be demonstrated. Also, interventions addressing harm avoidance, passive-dependent, schizoid and schizotypal personality traits may reduce suicide rates in psychosis, although future trials are needed to demonstrate this. Specifically, since risk is significantly higher in FEP, it is envisioned that early intervention services targeting suicide risk factors, including personality issues, may play a crucial role in suicide prevention in psychosis.

Author Contributions: J.-D.L.-M. and R.D. were the Principal Investigators of this multicenter work. M.C.-R., R.A.-A., E.S.-S., B.C.-F., R.D. and J.-D.L.-M. contributed in the process of protocol design, hypothesis generation, manuscript preparation and fulfilled the criteria for authorship. M.C.-R., R.A.-A., E.S.-S. and J.-D.L.-M. managed the bibliography searches. M.C.-R. wrote the first draft. R.A.-A., E.S.-S., B.C.-F. and R.D. conceived of the study, participated in its design, and implemented the project. R.A.-A., E.S.-S., B.C.-F., C.A., R.D. and J.-D.L.-M. contributed to the interpretation of results. All authors have read and agreed to the published version of the manuscript.

Funding: This study was supported by the Universidad Autónoma de Madrid (Spain) and European Union via the Intertalentum Project Grant-Marie Skłodowska Curie Actions (GA 713366) to J.-D.L.-M., which also funded the APC. R.A.-A. acknowledges funding support from the Spanish Carlos III Health Institute via a Miguel Servet grant which covers her salary (CP18/00003), which is being carried out at Fundación Instituto de Investigación Marqués de Valdecilla (Santander, Spain). E.S.-S.'s salary comes from the Spanish Agencia Estatal de Investigación via a Juan de la Cierva Training grant (FJC2019-042390-I/AEI/10.13039/501100011033). CA was supported by the Spanish Ministry of Science and Innovation. Instituto de Salud Carlos III (SAM16PE07CP1, PI16/02012, PI19/024), cofinanced by ERDF Funds from the European Commission, "A way of making Europe", CIBERSAM. Madrid Regional Government (B2017/BMD-3740 AGES-CM-2), European Union Structural Funds. European Union Seventh Framework Program under grant agreements FP7-4-HEALTH-2009-2.2.1-2241909 (Project EU-GEI), FP7- HEALTH-2013-2.2.1-2-603196 (Project PSYSCAN) and FP7- HEALTH2013-2.2.1-2-602478 (Project METSY); and European Union H2020 Program under the Innovative Medicines Initiative 2 Joint Undertaking (grant agreement No 115916, Project PRISM, and grant agreement No 777394, Project AIMS-2-TRIALS), Fundación Familia Alonso and Fundación Alicia Koplowitz. M.C.-R., works as Clinical Psychologist at Virgen del Rocío University Hospital (Seville, 
Spain) via Consejería de Salud y Familias (Junta de Andalucía) 2020 grant which covers his salary (RH-0081-2020).

Institutional Review Board Statement: This is a systematic review and to the best of our knowledge the selected studies received ethical approval from the Local Institutional Review Boards in accordance with the guidelines of the Declaration of Helsinki.

Informed Consent Statement: This is a systematic review of previous peer-reviewed publications. Hence, no participants are directly involved in this research and accordingly, no informed consent is required.

Data Availability Statement: Datasets are available upon request, provided data policy access is complied with.

Acknowledgments: We acknowledge departmental support from our institutions mentioned above.

Conflicts of Interest: The authors declare that they have no competing interests concerning the subject of the study. Celso Arango has been a consultant to or has received honoraria or grants from Acadia, Angelini, Boehringer, Gedeon Richter, Janssen Cilag, Lundbeck, Minerva, Otsuka, Roche, Sage, Servier, Shire, Schering Plough, Sumitomo Dainippon Pharma, Sunovion and Takeda. The funders detailed above had no role in the design of the study; in the collection, analyses, or interpretation of data; in the writing of the manuscript, or in the decision to publish the results.

\section{References}

1. World Health Organization Suicide in the World. Global Health Estimates 2019. Available online: https://apps.who.int/iris/ bitstream/handle/10665/326948/WHO-MSD-MER-19.3-eng.pdf?sequence=1\&isAllowed=y (accessed on 8 July 2021).

2. Courtet, P.; Olié, E.; Debien, C.; Vaiva, G. Keep Socially (but Not Physically) Connected and Carry on: Preventing Suicide in the Age of COVID-19. J. Clin. Psychiatry 2020, 81, 20. [CrossRef]

3. Gunnell, D.; Appleby, L.; Arensman, E.; Hawton, K.; John, A.; Kapur, N.; Khan, M.; O'Connor, R.C.; Pirkis, J. COVID-19 Suicide Prevention Research Collaboration Suicide Risk and Prevention during the COVID-19 Pandemic. Lancet Psychiatry 2020, 7 , 468-471. [CrossRef]

4. Sher, L. The Impact of the COVID-19 Pandemic on Suicide Rates. QJM 2020, 113, 707-712. [CrossRef] [PubMed]

5. Kawohl, W.; Nordt, C. COVID-19, Unemployment, and Suicide. Lancet Psychiatry 2020, 7, 389-390. [CrossRef]

6. Oyesanya, M.; Lopez-Morinigo, J.; Dutta, R. Systematic Review of Suicide in Economic Recession. World J. Psychiatry 2015, 5, 243-254. [CrossRef] [PubMed]

7. CDC Information for Healthcare Professionals about Coronavirus (COVID-19) 2020. Available online: https://www.cdc.gov/ coronavirus/2019-ncov/hcp/index.html (accessed on 8 July 2021).

8. Calati, R.; Ferrari, C.; Brittner, M.; Oasi, O.; Olié, E.; Carvalho, A.F.; Courtet, P. Suicidal Thoughts and Behaviors and Social Isolation: A Narrative Review of the Literature. J. Affect. Disord. 2019, 245, 653-667. [CrossRef]

9. Holmes, E.A.; O'Connor, R.C.; Perry, V.H.; Tracey, I.; Wessely, S.; Arseneault, L.; Ballard, C.; Christensen, H.; Cohen Silver, R.; Everall, I.; et al. Multidisciplinary Research Priorities for the COVID-19 Pandemic: A Call for Action for Mental Health Science. Lancet Psychiatry 2020, 7, 547-560. [CrossRef]

10. Padron-Monedero, A.; Noguer-Zambano, I.; García, T.G.; Suárez, R.S.; Bobes, J.; Gili, M.; Pérez, V.; Roca, M.; Saiz-Ruiz, J. Suicide. The Post-COVID Era: A Time for Action. Rev. Psiquiatr. Salud. Ment. 2020, 13, 229-231. [CrossRef] [PubMed]

11. Moreno, C.; Wykes, T.; Galderisi, S.; Nordentoft, M.; Crossley, N.; Jones, N.; Cannon, M.; Correll, C.U.; Byrne, L.; Carr, S.; et al. How Mental Health Care Should Change as a Consequence of the COVID-19 Pandemic. Lancet Psychiatry 2020, 7, 813-824. [CrossRef]

12. Jongsma, H.E.; Gayer-Anderson, C.; Lasalvia, A.; Quattrone, D.; Mulè, A.; Szöke, A.; Selten, J.-P.; Turner, C.; Arango, C.; Tarricone, I.; et al. Treated Incidence of Psychotic Disorders in the Multinational EU-GEI Study. JAMA Psychiatry 2018, 75, 36-46. [CrossRef]

13. Morgan, C.; Lappin, J.; Heslin, M.; Donoghue, K.; Lomas, B.; Reininghaus, U.; Onyejiaka, A.; Croudace, T.; Jones, P.B.; Murray, R.M.; et al. Reappraising the Long-Term Course and Outcome of Psychotic Disorders: The AESOP-10 Study. Psychol Med. 2014, 44, 2713-2726. [CrossRef]

14. Hjorthøj, C.; Stürup, A.E.; McGrath, J.J.; Nordentoft, M. Years of Potential Life Lost and Life Expectancy in Schizophrenia: A Systematic Review and Meta-Analysis. Lancet Psychiatry 2017, 4, 295-301. [CrossRef]

15. Dutta, R.; Murray, R.M.; Allardyce, J.; Jones, P.B.; Boydell, J.E. Mortality in First-Contact Psychosis Patients in the U.K.: A Cohort Study. Psychol Med. 2012, 42, 1649-1661. [CrossRef]

16. Saha, S.; Chant, D.; McGrath, J. A Systematic Review of Mortality in Schizophrenia: Is the Differential Mortality Gap Worsening over Time? Arch. Gen. Psychiatry 2007, 64, 1123-1131. [CrossRef]

17. Brown, S.; Inskip, H.; Barraclough, B. Causes of the Excess Mortality of Schizophrenia. Br. J. Psychiatry 2000, $177,212-217$. [CrossRef] [PubMed] 
18. Palmer, B.A.; Pankratz, V.S.; Bostwick, J.M. The Lifetime Risk of Suicide in Schizophrenia: A Reexamination. Arch. Gen. Psychiatry 2005, 62, 247-253. [CrossRef]

19. Lopez-Morinigo, J.-D.; Ayesa-Arriola, R.; Torres-Romano, B.; Fernandes, A.C.; Shetty, H.; Broadbent, M.; Dominguez-Ballesteros, M.-E.; Stewart, R.; David, A.S.; Dutta, R. Risk Assessment and Suicide by Patients with Schizophrenia in Secondary Mental Healthcare: A Case-Control Study. BMJ Open 2016, 6, e011929. [CrossRef] [PubMed]

20. Lopez-Morinigo, J.-D.; Fernandes, A.C.; Shetty, H.; Ayesa-Arriola, R.; Bari, A.; Stewart, R.; Dutta, R. Can Risk Assessment Predict Suicide in Secondary Mental Healthcare? Findings from the South London and Maudsley NHS Foundation Trust Biomedical Research Centre (SLaM BRC) Case Register. Soc. Psychiatry Psychiatr. Epidemiol 2018, 53, 1161-1171. [CrossRef] [PubMed]

21. Ayesa-Arriola, R.; Alcaraz, E.G.; Hernández, B.V.; Pérez-Iglesias, R.; López Moríñigo, J.D.; Duta, R.; David, A.S.; Tabares-Seisdedos, R.; Crespo-Facorro, B. Suicidal Behaviour in First-Episode Non-Affective Psychosis: Specific Risk Periods and Stage-Related Factors. Eur. Neuropsychopharmacol. 2015, 25, 2278-2288. [CrossRef]

22. Ayesa-Arriola, R.; Terán, J.M.P.; Moríñigo, J.D.L.; Rivero, M.C.; Setién-Suero, E.; Al-Halabi, S.; Cuesta, M.J.; David, A.S.; CrespoFacorro, B. The Dynamic Relationship between Insight and Suicidal Behavior in First Episode Psychosis Patients over 3-Year Follow-Up. Eur. Neuropsychopharmacol. 2018, 28, 1161-1172. [CrossRef] [PubMed]

23. Dutta, R.; Murray, R.M.; Hotopf, M.; Allardyce, J.; Jones, P.B.; Boydell, J. Reassessing the Long-Term Risk of Suicide after a First Episode of Psychosis. Arch. Gen. Psychiatry 2010, 67, 1230-1237. [CrossRef]

24. Melle, I.; Johannesen, J.O.; Friis, S.; Haahr, U.; Joa, I.; Larsen, T.K.; Opjordsmoen, S.; Rund, B.R.; Simonsen, E.; Vaglum, P.; et al. Early Detection of the First Episode of Schizophrenia and Suicidal Behavior. Am. J. Psychiatry 2006, 163, 800-804. [CrossRef]

25. Castagnini, A.C.; Galeazzi, G.M. Acute and Transient Psychoses: Clinical and Nosological Issues. BJPsych. Adv. 2016, 22, 292-300. [CrossRef]

26. Hu, W.; Su, L.; Quiao, J.; Zhu, J.; Zhou, Y. COVID-19 Outbreak Increased Risk of Schizophrenia in Aged Adults. PsyChinaXiv 2020.

27. Chacko, M.; Job, A.; Caston, F.; George, P.; Yacoub, A.; Cáceda, R. COVID-19-Induced Psychosis and Suicidal Behavior: Case Report. SN Compr. Clin. Med. 2020, 2, 1-5. [CrossRef] [PubMed]

28. Lee, D.T.S.; Wing, Y.K.; Leung, H.C.M.; Sung, J.J.Y.; Ng, Y.K.; Yiu, G.C.; Chen, R.Y.L.; Chiu, H.F.K. Factors Associated with Psychosis among Patients with Severe Acute Respiratory Syndrome: A Case-Control Study. Clin. Infect. Dis. 2004, 39, 1247-1249. [CrossRef]

29. Hawton, K.; Sutton, L.; Haw, C.; Sinclair, J.; Deeks, J.J. Schizophrenia and Suicide: Systematic Review of Risk Factors. Br. J. Psychiatry 2005, 187, 9-20. [CrossRef] [PubMed]

30. Challis, S.; Nielssen, O.; Harris, A.; Large, M. Systematic Meta-Analysis of the Risk Factors for Deliberate Self-Harm before and after Treatment for First-Episode Psychosis. Acta Psychiatr. Scand. 2013, 127, 442-454. [CrossRef] [PubMed]

31. de Leon, J.; Baca-García, E.; Blasco-Fontecilla, H. From the Serotonin Model of Suicide to a Mental Pain Model of Suicide. Psychother. Psychosom. 2015, 84, 323-329. [CrossRef]

32. Hulbert, C.A.; Jackson, H.J.; McGorry, P.D. Relationship between Personality and Course and Outcome in Early Psychosis: A Review of the Literature. Clin. Psychol. Rev. 1996, 16, 707-727. [CrossRef]

33. Canal-Rivero, M.; Barrigón, M.L.; Perona-Garcelán, S.; Rodriguez-Testal, J.F.; Giner, L.; Obiols-Llandrich, J.E.; Ruiz-Veguilla, M. One-Year Follow-up Study of First Suicide Attempts in First Episode Psychosis: Personality Traits and Temporal Pattern. Compr. Psychiatry 2016, 71, 121-129. [CrossRef] [PubMed]

34. Silverman, M.M.; Berman, A.L.; Sanddal, N.D.; O'carroll, P.W.; Joiner, T.E. Rebuilding the Tower of Babel: A Revised Nomenclature for the Study of Suicide and Suicidal Behaviors. Part 2: Suicide-Related Ideations, Communications, and Behaviors. Suicide Life Threat Behav. 2007, 37, 264-277. [CrossRef] [PubMed]

35. Biondi-Zoccai, G.; Lotrionte, M.; Landoni, G.; Modena, M.G. The Rough Guide to Systematic Reviews and Meta-Analyses. HSR Proc. Intensive Care Cardiovasc. Anesth. 2011, 3, 161-173. [PubMed]

36. Moher, D.; Liberati, A.; Tetzlaff, J.; Altman, D.G.; PRISMA Group. Preferred Reporting Items for Systematic Reviews and Meta-Analyses: The PRISMA Statement. PLoS Med. 2009, 6, e1000097. [CrossRef] [PubMed]

37. World Health Organization (Ed.) The ICD-10 Classification of Mental and Behavioural Disorders: Diagnostic Criteria for Research; World Health Organization: Geneva, Switzerland, 1993; ISBN 978-92-4-154455-9.

38. American Psychiatric Association (Ed.) Diagnostic and Statistical Manual of Mental Disorders: DSM-IV-TR, 4th ed.; text revision; American Psychiatric Association: Washington, DC, USA, 2000; ISBN 978-0-89042-024-9.

39. American Psychiatric Association. DSM-5: Manual diagnóstico y estadístico de los trastornos mentales; Editorial Médica Panamericana: Buenos Aires, Argentina, 2016; ISBN 978-84-9835-810-0.

40. Ouzzani, M.; Hammady, H.; Fedorowicz, Z.; Elmagarmid, A. Rayyan-A Web and Mobile App for Systematic Reviews. Syst Rev. 2016, 5, 210. [CrossRef]

41. Albayrak, Y.; Ekinci, O.; Cayköylü, A. Temperament and Character Personality Profile in Relation to Suicide Attempts in Patients with Schizophrenia. Compr. Psychiatry 2012, 53, 1130-1136. [CrossRef]

42. Miralles, C.; Alonso, Y.; Verge, B.; Setó, S.; Gaviria, A.M.; Moreno, L.; Cortés, M.J.; Gutiérrez-Zotes, A.; Vilella, E.; Martorell, L. Personality Dimensions of Schizophrenia Patients Compared to Control Subjects by Gender and the Relationship with Illness Severity. BMC Psychiatry 2014, 14, 151. [CrossRef]

43. Jovanovic, N.; Kudumija Slijepcevic, M.; Podlesek, A. Personality Traits in Suicidal and Homicidal Subjects with Schizophrenia. J. Forensic Psychiatry Psychol. 2019, 30, 76-88. [CrossRef] 
44. Teraishi, T.; Hori, H.; Sasayama, D.; Matsuo, J.; Ogawa, S.; Ishida, I.; Nagashima, A.; Kinoshita, Y.; Ota, M.; Hattori, K.; et al. Relationship between Lifetime Suicide Attempts and Schizotypal Traits in Patients with Schizophrenia. PLoS ONE 2014, 9, e107739. [CrossRef]

45. Canal-Rivero, M.; Lopez-Moriñigo, J.D.; Barrigón, M.L.; Perona-Garcelán, S.; Jimenez-Casado, C.; David, A.S.; Obiols-Llandrich, J.E.; Ruiz-Veguilla, M. The Role of Premorbid Personality and Social Cognition in Suicidal Behaviour in First-Episode Psychosis: A One-Year Follow-up Study. Psychiatry Res. 2017, 256, 13-20. [CrossRef] [PubMed]

46. Canal-Rivero, M.; Velasco-Barbancho, E.; Barrigón, M.L.; Villar-Cabeza, F.; Obiols-Llandrich, J.E.; Crespo-Facorro, B.; RuizVeguilla, M. Personality Traits, Theory of Mind and Their Relationship with Multiple Suicide Attempts in a Sample of First Episode Psychosis Patients: One-Year Follow-up Study. J. Affect. Disord. 2019, 256, 176-182. [CrossRef]

47. Canal-Rivero, M.; Lopez-Moriñigo, J.-D.; Barrigón, M.-L.; Ayesa-Arriola, R.; Crespo-Facorro, B.; Ruiz-Veguilla, M.; ObiolsLlandrich, J.E. Suicidal Behavior and Personality Traits Contribute to Disability in First-Episode Psychosis: A 1-Year Follow-up Study. Suicide Life Threat Behav. 2019, 49, 798-810. [CrossRef]

48. Campos, M.S.; Garcia-Jalon, E.; Gilleen, J.K.; David, A.S.; Peralta, V.M.D.; Cuesta, M.J. Premorbid Personality and Insight in First-Episode Psychosis. Schizophr Bull. 2011, 37, 52-60. [CrossRef] [PubMed]

49. Jaspers, K. General Psychopathology; Johns Hopkins, paperbacks, Ed.; Johns Hopkins University Press: Baltimore, MD, USA, 1997; ISBN 978-0-8018-5775-1.

50. Kretschmer, E.; Fundación Archivos de Neurobiología. El Delirio Sensitivo de Referencia: Contribución al Problema de la Paranoia y a la Teoría Psiquiátrica del Carácter; introducción y capítulo adicional de Wolfgang Kretschmer; Fundación Archivos de Neurobiología. Triacastela: Madrid, Spain, 2000; ISBN 978-84-930914-2-2.

51. Sevilla-Llewellyn-Jones, J.; Cano-Domínguez, P.; de-Luis-Matilla, A.; Peñuelas-Calvo, I.; Espina-Eizaguirre, A.; Moreno-Kustner, B.; Ochoa, S. Personality Traits and Psychotic Symptoms in Recent Onset of Psychosis Patients. Compr. Psychiatry 2017, 74, 109-117. [CrossRef] [PubMed]

52. McCrae, R.R.; John, O.P. An Introduction to the Five-Factor Model and Its Applications. J. Pers. 1992, 60, 175-215. [CrossRef] [PubMed]

53. Cloninger, C.R. A Psychobiological Model of Temperament and Character. Arch. Gen. Psychiatry 1993, 50, 975-990. [CrossRef] [PubMed]

54. Millon, T. Modern Psychopathology: A Biosocial Approach to Maladaptive Learning and Functioning; W.B. Saunders: Philadelphia, PA, USA, 1969; ISBN 978-0-7216-6385-2.

55. Keshavan, M.S.; Diwadkar, V.A.; Montrose, D.M.; Stanley, J.A.; Pettegrew, J.W. Premorbid Characterization in Schizophrenia: The Pittsburgh High Risk Study. World Psychiatry 2004, 3, 163-168.

56. Simonsen, E.; Haahr, U.; Mortensen, E.L.; Friis, S.; Johannessen, J.O.; Larsen, T.K.; Melle, I.; Opjordsmoen, S.; Rund, B.R.; McGlashan, T.; et al. Personality Disorders in First-Episode Psychosis. Personality 2008, 2, 230-239. [CrossRef]

57. David, A.S. Insight and Psychosis. Br. J. Psychiatry 1990, 156, 798-808. [CrossRef]

58. Lopez-Morinigo, J.-D.; Di Forti, M.; Ajnakina, O.; Wiffen, B.D.; Morgan, K.; Doody, G.A.; Jones, P.B.; Ayesa-Arriola, R.; CanalRivero, M.; Crespo-Facorro, B.; et al. Insight and Risk of Suicidal Behaviour in Two First-Episode Psychosis Cohorts: Effects of Previous Suicide Attempts and Depression. Schizophr. Res. 2019, 204, 80-89. [CrossRef]

59. Cuesta, M.J.; Peralta, V.; Campos, M.S.; Garcia-Jalon, E. Can Insight Be Predicted in First-Episode Psychosis Patients? A Longitudinal and Hierarchical Analysis of Predictors in a Drug-Naïve Sample. Schizophr Res. 2011, 130, 148-156. [CrossRef] [PubMed]

60. Amador, X.F.; David, A.S. Insight and Psychosis, 2nd ed.; Amador, X.F., David, A.S., Eds.; Oxford University Press: Oxford, UK, 2004; ISBN 978-0-19-852568-4.

61. Lopez-Morinigo, J.-D.; Ajnakina, O.; Martínez, A.S.-E.; Escobedo-Aedo, P.-J.; Ruiz-Ruano, V.G.; Sánchez-Alonso, S.; Mata-Iturralde, L.; Muñoz-Lorenzo, L.; Ochoa, S.; Baca-García, E.; et al. Can Metacognitive Interventions Improve Insight in Schizophrenia Spectrum Disorders? A Systematic Review and Meta-Analysis. Psychol. Med. 2020, 50, 2289-2301. [CrossRef] [PubMed]

62. Lysaker, P.H.; Klion, R.E. Recovery, Meaning-Making, and Severe Mental Illness: A Comprehensive Guide to Metacognitive Reflection and Insight Therapy, 1st ed.; Routledge, Taylor \& Francis Group: Oxfordshire, UK, 2018; ISBN 978-1-138-20838-4.

63. Canal-Rivero, M. Factores de Riesgo de Suicidio En Primeros Episodios Psicóticos; Universitat Autónoma de Barcelona: Barcelona, Spain, 2018.

64. Upthegrove, R.; Abu-Akel, A.; Chisholm, K.; Lin, A.; Zahid, S.; Pelton, M.; Apperly, I.; Hansen, P.C.; Wood, S.J. Autism and Psychosis: Clinical Implications for Depression and Suicide. Schizophr. Res. 2018, 195, 80-85. [CrossRef]

65. Rombey, T.; Doni, K.; Hoffmann, F.; Pieper, D.; Allers, K. More Systematic Reviews Were Registered in PROSPERO Each Year, but Few Records' Status Was up-to-Date. J. Clin. Epidemiol. 2020, 117, 60-67. [CrossRef]

66. Reed, G.M.; First, M.B.; Kogan, C.S.; Hyman, S.E.; Gureje, O.; Gaebel, W.; Maj, M.; Stein, D.J.; Maercker, A.; Tyrer, P.; et al. Innovations and Changes in the ICD-11 Classification of Mental, Behavioural and Neurodevelopmental Disorders. World Psychiatry 2019, 18, 3-19. [CrossRef]

67. Peralta, V.; Cuesta, M.J. How Many and Which Are the Psychopathological Dimensions in Schizophrenia? Issues Influencing Their Ascertainment. Schizophr. Res. 2001, 49, 269-285. [CrossRef]

68. Van Os, J. Is There a Continuum of Psychotic Experiences in the General Population? Epidemiol. Psichiatr. Soc. 2003, 12, $242-252$. [CrossRef] [PubMed] 
69. Jablensky, A. Living in a Kraepelinian World: Kraepelin's Impact on Modern Psychiatry. Hist. Psychiatry 2007, 18, 381-388. [CrossRef]

70. Artigas, F.; Schenker, E.; Celada, P.; Spedding, M.; Lladó-Pelfort, L.; Jurado, N.; Núñez, M.; Santana, N.; Troyano-Rodriguez, E.; Riga, M.S.; et al. Defining the Brain Circuits Involved in Psychiatric Disorders: IMI-NEWMEDS. Nat. Rev. Drug Discov. 2017, 16, 1-2. [CrossRef] 